\title{
Sobre el nombre y el quién de los jornaleros andaluces
}

FÉlix TAlego Vázquez*

\section{A vueltas con la palabra}

La palabra "jornalero", es empleada con bastante frecuencia, tanto por los propios que así se consideran como por los medios de comunicación y los investigadores sociales. Sin embargo, a poca familiaridad que se tenga con el medio socio-cultural donde viven quienes así se llaman -o son llamados- o, por lo menos, con la amplia literatura que sobre ellos se ha producido en Andalucía, se comprueba que los usos que se han dado y dan al término distan mucho de ser coincidentes. Es así porque estamos ante uno de esos términos que, lejos de ser planos, meramente descriptivos -en sentido estricto ningún término lo es-, está cargado de densas y diversas connotaciones, confusas, y, lo que es peor, confundidas, ignoradas o inadvertidas en muchos casos por quienes se sirven del término y creen, ingenuamente, que al emplearlo están simplemente describiendo una realidad también plana y diáfana, observable directamente en la escena social. Estas ingenuidades no pueden pasar inadvertidas para los científicos sociales, quienes, precisamente, estamos obligados a familiarizarnos con el lastre de las palabras, pues sabemos que es a través de las palabras, de los campos lexicográficos, como se construyen las diversas interpretaciones de la realidad social, ninguna de ellas neutra, todas signadas ideológicamente y cargadas de valoraciones y prejuicios. Las descripciones son siempre interpretaciones, (Geertz, 1992: 19-41), aunque, eso sí, no todas son igualmente arbitrarias, pues algunas de ellas, por así decirlo, construyen interpretaciones más ajustadas a los hechos y a los campos de fuerzas sociales. En este artículo vamos a procurar poner de relieve que no está ni mucho menos claro quiénes o qué agregado, grupo o colectivo de personas caben tras este vocablo.

Si atendemos al uso que la sociedad rural andaluza hizo de la palabra en el pasado, al menos desde finales del XIX, parece claro que se trataba de una de esas expresiones cargadas de contenido peyorativo con las que otros sectores sociales se referían a los trabajadores asalariados de la agricultura, como trabajadores que han de atenerse exclusivamente al

* Grupo de investigación GEISA. Departamento de Antropología Social. Universidad de Sevilla. 
jornal, el salario eventual por el trabajo realizado interina u ocasionalmente. Unas veces, o en algunas comarcas, eran llamados jornaleros y en otras braceros, dos términos básicamente sinónimos. Según esta primera acepción, se trataba de un sector social identificado por el resto de la sociedad según su forma específica de acceso al trabajo, es decir por su forma de inserción en las relaciones sociales de producción. Se incidía así en su condición obrera, pero más específicamente aun, en su condición obrera eventual. Si así les llamaban era para indicar que ocupaban la posición más endeble o precaria de la sociedad rural. El sentido peyorativo nacía justamente por incidir la palabra en la condición insegura y frágil del jornal. El conjunto de estos trabajadores quedaban de esta forma diferenciados por el lenguaje, no sólo del conjunto de los propietarios, sino del resto de los trabajadores atenidos a un salario estable o fijo.

Esta claro, por otra parte, que, por lo menos hasta las últimas décadas, el apelativo no era del gusto de aquéllos a quienes se dirigía. Así se desprende de dos libros fundamentales, escritos ambos por testigos de primera mano, el estudio de Díaz del Moral (1984) y la biografía de Rosado (1979), pero lo mismo puede afirmarse cuando se repasa la bibliografía que se ha ocupado de ese período y que ha manejado documentos y testimonios de la época (Abbad, F., Bernal, A.M., 1971; Acosta, J., 1979; Artola, M., Bernal, A. M y Contreras; J, 1978; Bernal, A.M., 1974; Brenan, Y. 1962; Martínez Alier, 1968). Los que así eran llamados preferían llamarse a sí mismos como "obreros del campo" o simplemente "obreros" o "trabajadores", eludiendo el estigma negativo de los otros términos y autoidentificándose y queriendo confundirse con el grueso de la clase obrera. De hecho, de la abundante relación de agrupaciones sindicales de las que da cuenta Díaz del Moral en su prolijo y bien documentado estudio, referentes en su mayoría a la provincia de Córdoba, pero también de Cádiz, Málaga o Sevilla, ninguna de ellas recoge en sus rótulos el término jornalero o bracero, muy al contrario de lo que ocurre con el de obrero, que está presente en casi todas. Y así ha debido ser también en el resto de Andalucía; de hecho, en nuestro trabajo de campo por las campiñas de Ecija, Osuna y Estepa, en el Bajo Guadalquivir, en la Sierra onubense, hemos comprobado que los jornaleros de más edad suelen rehusar llamarse a sí mismos como tales y prefieren la expresión, más neutra para ellos, de "obrero del campo".

Pero la relación de los nombres con la cosa ha venido a complicarse en la última época de resurgimiento del movimiento jornalero, en los años de la "transición": observamos en este último período que los sindicatos con implantación en el sector, especialmente el Sindicato de Obreros del Campo (SOC) y muchas agrupaciones de CC.OO. han usado sistemáticamente la palabra jornalero, lo que constituye toda una novedad que no debe pasarnos desapercibida: parece con ello que los protagonistas han querido usar el término otrora denostado precisamente dotándolo de un contenido político autoafirmador de la identidad específica del colectivo. En estos años, los jornaleros sindicalistas han querido que el grupo se autoidentifique -y sea identificado- no como obreros sin más, sino como trabajadores 
del campo que quieren así llamar la atención sobre su especificidad y que reivindican una solución a su situación precaria en el campo. Con la nueva estrategia de identificación se ha querido señalar que las soluciones que debían arbitrarse a la problemática del colectivo tenían que ser específicas. Una solución distinta que pasaba por la entrega de tierras, por "el reparto", anhelo secular de los trabajadores del campo andaluz y sólo de ellos, que, por tal razón, no son obreros sin más, sino jornaleros.

Se ve pues cómo en el transcurso de un siglo la palabra ha experimentado un cambio importante, no tanto en su contenido sustantivo -antes, como ahora, designa a los trabajadores por cuenta ajena eventuales de la agricultura- pero sí en la valoración que tal apelativo merece a quienes son nombrados por él: en el pasado fue una valoración negativa, empleada sobre todo por quienes no lo eran en el medio rural, mientras que en los años de la transición y hasta estos últimos años en los que parece cumplirse la "agonía final de la conciencia jornalera" (Ortí, 1984) esa valoración se ha tornado positiva. La evolución de la palabra se asemeja a la de esos vocablos que comienzan siendo utilizados como armas arrojadizas, para estigmatizar a determinados grupos, pero que terminan siendo asumidos por ellos en el mismo proceso de su concienciación crítica y reconocimiento y defensa de sus derechos. Una palabra estigmatizada y estigmatizante ha llegado a cargarse de contenido socio-político impugnador.

El carácter específico, distintivo de este sector de los trabajadores andaluces es, por lo demás, algo reconocido implícita o explícitamente por la generalidad de los estudiosos que se han acercado al tema y hay, pues, acuerdo en reconocer que la palabra no establece una distinción arbitraria, insustancial, sino que, muy al contrario, reconoce una situación específica. Una situación, por otra parte, de gran relevancia social y política en la historia reciente de Andalucía: durante un siglo largo los jornaleros han sido el sector social protagonista del conjunto de la clase obrera andaluza, no sólo por su importancia numérica en el conjunto del territorio andaluz y su función clave en las relaciones sociales de producción agraria, sino por su papel crucial en las luchas sociales, que ha tenido que ser reconocida y resaltada incluso por aquellos que han procurado hacer un estudio global del movimiento obrero en la historia de España (Tuñón de Lara, 1978). De hecho, el anhelo secular de conquista de tierras ha contribuido poderosamente ha configurar una historia social andaluza distinta a la de otros países del Estado español, hasta el punto de haber convertido a la propiedad de la tierra en un problema capital, en un "marcador simbólico" de la etnicidad andaluza en su conjunto, frente al que todos los andaluces han tenido que posicionarse, aunque no estuvieran relacionados directamente con la tierra (Moreno, 1984, Martínez, M. R., 1993).

Sin embargo, la controversia aparece cuando se trata de dictaminar las causas que explican ese comportamiento especial durante un largo siglo, pero también cuando se buscan 
respuestas que expliquen la postración jornalera que se hace más y más evidente en los últimos años. Una respuesta satisfactoria a estas cuestiones claves sólo puede obtenerse si logramos señalar los contenidos culturales conformadores de la identidad de este sector social, en definitiva, saber quiénes eran "los luchadores que tan gallardamente se batían"1. Repasemos primero algunos enfoques que han tenido y tienen mucho predicamento en Andalucía, pero que conducen a conclusiones equivocadas.

\section{La tradición de los "estudios campesinos" y su relación con el problema jornalero.}

Un tipo de enfoque que gozó de gran predicamento entre historiadores y sociólogos, trató de identificar el movimiento jornalero andaluz con un tipo de protesta que se encontraría a caballo entre las protestas prepolíticas o arcaicas y las plenamente políticas o modernas (Hobsbawn, 1983). Esta tesis se emparenta con aquélla que sostenía que se trató de rebeliones milenaristas e irracionales. Estos argumentos han sido convenientemente rebatidos (Moreno, 1993: 59-62), y pertenecen a un debate afortunadamente superado. Otros autores. sin embargo, mantienen viva una corriente teórica que, en esencia, consiste en querer explicar el caso andaluz aplicando, con ligeros retoques, los conceptos principales de la tradición de los "estudios campesinos". El problema nuclear para estos autores es determinar qué une y qué separa a los jornaleros del resto de los sectores sociales presentes en el campo andaluz, particularmente a los campesinos. Pero esta es justamente una interrogación un tanto peculiar -quizás se podría decir que marginal-, si se la relaciona con el ámbito general de los "estudios campesinos".

Ciertamente, la temática central de los estudios de los agraristas ha girado siempre en torno a los condicionantes y a la evolución económico-social, política e ideológica de los campesinos, entendidos éstos globalmente como productores agrícolas directos que mediante alguna fórmula de tenencia de la tierra (aparcería, colonato, arriendo, propiedad, cesión...) están en condiciones de tomar decisiones sobre la gestión de la explotación y se encuentran sometidos -influenciados según Redfield (1956: 31)- económica y políticamente a otras clases sociales o estamentos que mediante diversas fórmulas de dependencia les despojan del excedente. Esta es una definición suficientemente amplia y comprensiva como para que pueda integrar las caracterizaciones clásicas que se han hecho del campesinado, aquellas más sistemáticamente citadas y que han orientado el grueso de las investigaciones ${ }^{2}$. Todas estas investigaciones mantienen un importante punto de confluen-

1. Expresión de Díaz del Moral que recoge Moreno (1993a, p. 55).

2 Entre los autores más conocidos, que no siempre llegan a conclusiones coincidentes, se encuentran: Hobsbawm (1976 y 1983), Alavi (en Hobsbawm y Alavi, 1976), Shanin (1979, 1983), Wolf (1971 y 1972), 
cia: en todos los casos se establecen unas limitaciones más allá de las cuales no cabría hablar -o sería al menos discutible- de campesinos: han de tener la base principal de su economía doméstica como productores agrícolas directos responsables de su explotación.

Por tanto, en sentido riguroso, los trabajadores agrícolas por cuenta ajena, aun con ser productores agrícolas, no serían campesinos, pues no gestionan por sí mismos la explotación, sino que trabajan a las órdenes de terceros. Se constata un desinterés por el sector social de los jornaleros en todos estos análisis. Los trabajadores asalariados quedan fuera del campo de interés de esta, por otra parte, rica corriente teórica, simple y llanamente porque se considera que no participan de esa supuesta lógica de la producción doméstica campesina, al ser conceptualizados ya decididamente como clase obrera, como un subproducto del capitalismo o del mundo urbano, netamente diferenciados de los campesinos ${ }^{3}$.

Pero he ahí que el grueso de los agraristas que han estudiado en Andalucía han tenido como interés fundamental investigar al sector social jornalero y demostrar que no es asimilable o confundible sin más al proletariado, sino que. precisamente, por unas u otras razones, guardan similitudes con el conjunto del campesinado andaluz. Las confusiones, las contradicciones de los "campesinistas" andaluces e incluso las equívocas consecuencias políticas que algunos extraen de sus planteamientos, se deben, en buena medida, a la forma inadecuada cómo se pretende ensamblar el análisis del caso en Andalucía a la corriente general de los "estudios campesinos".

Galeski (1977), Huizer (1973), Lehmann y Zemelman (1975) y otros. Para muchos de ellos, hay una referencia teórica común, el esfuerzo llevado a cabo a principios de siglo por Chayanov por conceptualizar y comprender adecuadamente la especificidad de la lógica de la producción doméstica campesina (Chayanov, 1974). Robert Redfield (1955; 1956) desarrolla un tipo de planteamientos en principio distintos, porque las conclusiones de sus trabajos tienden a infravalorar lo campesino como algo arcaico que debe ser paulatinamente sustituido por lo urbano o capitalista. A pesar de ello, nosotros creemos que la tradición de los "estudios campesinos" debe a Redfield más de lo que los citados estarían dispuestos a reconocer.

${ }^{3}$ En el fondo, toda la sociología llamada de los "estudios campesinos" es deudora, aunque no se reconozca, de los planteamientos teóricos desarrollados por Lenin y Kautsky (1974) sobre las formas de penetración del capitalismo en la agricultura, interpretación que fue reformulada después por Redfield, que minimizó las consecuencias sociales negativas del proceso mediante su teoría del continuum rural-urbano. Lo esencial a todos estos planteamientos es que conciben la existencia de dos mundos regidos por reglas parcialmente autónomas, el rural, precapitalista o menos moldeado por el capitalismo y el urbano o plenamente capitalista. Sus averiguaciones han estado orientadas sobre todo a sociedades donde las consecuencias del desarrollo capitalista no estaban consumadas. Parece conveniente, por tanto, que los instrumentos conceptuales de esta corriente teórica sean puestos en cuarentena cuando se estudian sociedades plenamente integradas al sistema capitalista internacional y cón un desarrollo ya secular de las formas de organización capitalistas en la agricultura, como es el caso de Andalucía. 
En 1976, en la revista "Agricultura y Sociedad", se publicó ya un artículo de gran importancia para el desarrollo posterior de este debate; nos referimos al trabajo elaborado por Sevilla-Guzmán y Pérez Yruela (1976). En dicho artículo definen al campesinado como “...aquel sector social integrado por unidades familiares de producción y consumo cuya organización social y económica se basa en la explotación agraria del suelo, independientemente de que posean o no tierra y de la forma de tenencia que las vincule a ella y cuya característica red de relaciones sociales se desarrolla en comunidades rurales, las cuales mantienen una relación asimétrica de dependencia, y en muchos casos explotación, con el resto de la sociedad en términos de poder político, cultural y económico" (Sevilla-Guzmán y Pérez Yruela, 1976, pp 28-29; Sevilla-Guzmán, 1979, p. 25).

Esta definición, heredera sin duda de la tradición general a la que nos estamos refiriendo, pone, sin embargo, énfasis en dos aspectos de consecuencias teóricas y metodológicas importantes: incluye en el mismo sector social - $i$ clase?- a los pequeños productores autónomos y a los asalariados agrícolas, a los que ellos llaman "campesinos sin tierra", y, en segundo lugar, considera a los núcleos rurales como "comunidades rurales". El concepto de "comúnidad campesina" que emplean Sevilla-Guzmán y Pérez Yruela en estos trabajos es una reelaboración del propuesto por Galeski (Galeski, 1977), como lo reconoce Sevilla-Guzmán en su caracterización sociológica del latifundio (Sevilla-Guzmán, 1980: 32), pero hemos de advertir que Galeski lleva a cabo a su vez una reelaboración de un concepto del que se ha hecho mucho uso en la Antropología Social y que se debe a Redfield (1955), que concibió la comunidad típica como un asentamiento social, pequeño y, ante todo, homogéneo socialmente y con fuertes lazos de solidaridad interna. Pueden tomarse en cuenta las matizaciones que se quiera, como lo hace de hecho Sevilla-Guzmán (1980: 32), queriendo distanciarse de algunas implicaciones de tal concepto, pero cuando no se renuncia a utilizarlo es necesario deducir que se quiere enfatizar la vigencia, por lo menos, de una cierta afinidad o correspondencia en cuanto a la situación y, por tanto, en cuanto a los intereses de los distintos sectores presentes, en este caso, en los pueblos andaluces.

De hecho, se sostiene que los jornaleros participan de una posición social semejante o asimilable a la de los productores agrícolas directos (pequeños propietarios, arrendatarios, aparceros), por contribuir todos ellos al beneficio del "resto de la sociedad", pero, primeramente, de la minoría latifundista. Esta minoría latifundista, y sólo ellos, quedarían fuera del ámbito de la "comunidad campesina" (Sevilla-Guzmán y Pérez Yruela, 1976: 28-34). La dependencia común de los que integran la "comunidad" reforzaría, según los autores, los vínculos entre jornaleros y pequeños propietarios, que estarían "unidos por un sistema de lazos y relaciones sociales, por intereses comunes, pautas compartidas de normas y va- 
lores aceptados; por la conciencia de ser distintos a los demás grupos..." (Sevilla-Guzmán, 1980: $32-33)^{4}$.

En todos estos textos evitan hablar de clases sociales en el campo, prefiriendo recurrir al concepto de "segmentación vertical", elaborado por Shanin (1983: 246) y que deriva de la interpretación de las "lealtades primordiales" de Alavi (1976: 46-125). Siguiendo esta línea argumental desembocan en la afirmación de que, tanto campesinos con tierra como campesinos sin tierra, en momentos de polarización extrema, actuarían "...como un todo realizando una acción de clase" (Sevilla-Guzmán y Pérez Yruela, 1976: 32). Esta claro que el objetivo que persiguen los autores con toda esta argumentación es fundamentar teóricamente la confluencia en las luchas sociales del campo andaluz de los pequeños campesinos y de los jornaleros. Quieren, por ello, caracterizar las protestas de los jornaleros andaluces como "protestas campesinas", y no tanto como luchas obreras clásicas. En estudios más recientes, estos autores (Sevilla-Guzmán y González de Molina, 1993; González de Molina, M., 1993) han intentado profundizar por esta misma vía, aportando algunos elementos nuevos, pero mánteniendo en lo sustancial el mismo esquema interpretativo. Pretenden ahora que el campesinado andaluz habría mantenido, al menos en parte, una lógica y unas prácticas no del todo capitalistas, o no del todo subsumidas a la lógica capitalista de la maximización del beneficio 5 . Este hecho, según ellos, podría posibilitar, en determinadas condiciones, la recuperación de una producción campesina en Andalucía, más sustentable ecológicamente y más justa socialmente.

Esto supone, aunque no se plantee abiertamente, negar las conclusiones de los trabajos de Martínez Alier (1967) o el más reciente de Antonio Miguel Bernal (1988) en cuanto al carácter inequívocamente capitalista de los latifundios andaluces, minimizando o cercenando las consecuencias directas que de tales estudios se derivan en cuanto al carácter claramente capitalista de las relaciones sociales de producción en el campo andaluz en los dos últimos siglos ${ }^{6}$. Todas estas reflexiones se presentan, además, con una gran imprecisión histórica, pues, en los escritos que comentamos, no sabemos bien cuándo se refieren a los

\footnotetext{
${ }^{4}$ Este concepto ha continuado siendo operativo para Sevilla-Guzmám, como lo demuestra un artículo más reciente elaborado en colaboración con González de Molina, en el que vuelven a emplear el concepto, sólo con ligeros retoques (González de Molina, M.y Sevilla-Guzmán E, 1993: 71-72).

${ }^{5}$ Emplean los conceptos de "subsunción formal" y "real", conceptos marxistas recuperados, sobre todo, por Godelier (1987). Valiéndose de este repertorio teórico, pretenden convencernos de que la lógica campesina no capitalista se habría mantenido en Andalucía merced a que estaría sólo "subsumida formalmente" a la lógica de la acumulación capitalista.

${ }^{6}$ González de Molina dice al respecto: "Dada la escasa presencia del capital técnico, el núcleo económico de esta forma de explotación (el latifundio andaluz) reside en la preponderancia casi absoluta de esta forma de
} 
campesinos que asistieron a las desamortizaciones y cuándo a quienes en los últimos años viven pendientes de las oscilaciones de los precios en el centro de Europa y de las subvenciones de Bruselas. Los jornaleros quedarían incluidos en esas "comunidades campesinas", lo que se justificaría por la pervivencia en los grupos domésticos jornaleros de una "racionalidad no basada en el lucro" (Sevilla-Guzmán y González de Molina, 1993: 85), algo posible, según los autores, por no haberse cumplido con los jornaleros tampoco -nunca se nos especifica si los del siglo pasado o los que hoy cobran el Subsidio de Desempleo- la "subsunción real" a la racionalidad capitalista.

Esta corriente de interpretación, aunque no se explicita -por el estilo científico que mantienen los artículos- conduce a conclusiones llamativas, como es, por ejemplo, la virtualidad de un horizonte social y político distinto en el que, liberados los campesinos y los jornaleros de la estructura de dominación latifundista -que sólo era, recordémoslo, dominación o "subsunción formal"- podrían desarrollar las potencialidades de solidaridad y de equilibrio ecológico. Subyace a todo el planteamiento un prejuicio ideológico -entendiendo ideológico como visión sesgada de la realidad-, según el cual sólo los ámbitos -espacios sociales- no acabadamente ganados por el capitalismo conservarían las condiciones para un posible desarrollo sustentado en la solidaridad y el apoyo mutuo. Esta era, en esencia, la tesis de los populistas rusos, los teóricos que a finales del pasado siglo y principios de éste intentaron elaborar una teoría política y un programa de acción revolucionaria a partir de las tendencias socialistas innatas de la obsina o comuna campesina rusa?

propiedad... , la relación jurídica de apropiación de la tierra se convierte en condición fundamental de esta forma de explotación... La cooperación simple y la escasa división del trabajo en el seno de la explotación no logran tampoco despojar al trabajador de su "saber" agrícola y del dominio de las operaciones del proceso de trabajo. El latifundio debe considerarse, pues, como una forma de explotación (sólo) $<<$ formalmente capitalista $\rangle$... La tradicional conexión establecida entre latifundismo y descampesinización no tiene por qué ser una relación general y universalmente válida." (González de Molina, 1993: 273). Y También: "de su presencia (del latifundio) no puede concluirse el inicio de un proceso que conduzca a la desaparición de las pequeñas explotaciones campesinas ni, necesariamente, a la pérdida del carácter campesino de dichas comunidades." (Sevilla-Guzmán y González de Molina, 1993: 121-22). El subrayado es nuestro.

${ }^{7}$ El propio Eduardo Sevilla-Guzmán, en otro artículo nos da cuenta de estos planteamientos: el elemento central del populismo ruso sería: “...evitar el desarrollo del capitalismo a través de las formas de organización campesina...mediante la existencia de una especie de instinto socialista campesino..., reacia a aceptar las formas de organización de la producción que introduce el capitalismo en el campo y que constituyen las formas solidarias de trabajo en común del campesinado tradicional, en cuyo universo sociocultural el concepto de salario es difícil de ser aceptado, tal como aparece en la teoría económica convencional." (Sevilla-Guzmán, 1988: 33). Al final del artículo el autor manifiesta explícitamente la conexión que existe entre el movimiento jornalero andaluz y tales rasgos del populismo ruso (op. cit: 45). 
Estos planteamientos nos sugieren, ciertamente, un horizonte esperanzador, incluso pueden incorporarse a los discursos legitimadores de un cierto tipo de protesta jornalera. ya claramente residual (Talego, 1995, 1996a) o a un cierto ecologismo que quiere ver en los jornaleros andaluces poco menos que los sujetos "no contaminados" que encabezarán la lucha contra todo lo contaminado (Garrido, F. 1993). Pero son todos planteamientos ilusos, fruto, como hemos puesto de manifiesto. de graves confusiones teóricas acerca de un supuesto comunitarismo rural andaluz.

\section{Los pueblos andaluces no son "comunidades campesinas"}

Paradójicamente, el mismo autor del que ellos partían en su definición de "comunidad campesina", B. Galeski, nos da la clave para poner en cuestión la aplicabilidad del concepto a Andalucía: Este autor plantea que, bajo el capitalismo "la aldea" puede verse desde dos ángulos distintos: “...primero, como una comunidad en que aparece una estructura de clases análoga a la de las ciudades, y segundo, como un estrato social que...se acerca a la posición de la clase obrera y en ciertos países llega incluso a convertirse en la clase social más baja”. Más adelante se pregunta: “¿en qué situaciones sociales la comunidad rural actúa todavía como clase y en qué situaciones es necesario tener en cuenta sobre todo la diferenciación interna de clase existente en el campo?" (Galeski, 1977: 184 y 186). Para nosotros la respuesta no ofrece dudas. No es éste el lugar para llevar a cabo una crítica -que juzgaríamos pertinente- sobre la consideración de los pequeños propietarios de la agricultura andaluza en este siglo como campesinos portadores de una lógica diferente a la capitalista. pero vamos, al menos, a demostrar que los jornaleros tienen que ser considerados una clase social surgida del capitalismo y plenamente inserta en su lógica, con una situación social y unas prácticas netamente diferenciadas y a menudo contrapuestas a la de los propietarios de la tierra, sean éstos latifundistas, medianos o pequeños propietarios. Un repaso, aunque sea breve, a las características principales del movimiento jornalero andaluz de este siglo nos va a ayudar a caracterizar los rasgos determinantes de la estructura social del medio rural andaluz.

Los estudios más conocidos y citados sobre estos movimientos andaluces parecen dar crédito, al menos esta es la lectura que se ha extraído de ellos en repetidas ocasiones, a una interpretación que considera que fueron el fruto de una gran alianza de clase entre los jornaleros y los pequeños propietarios. Díaz del Moral dice, por ejemplo, que en los momentos de auge del movimiento anarcosindicalista se unieron a él muchos colonos, arrendatarios, minifundistas, y que sin el apoyo de éstos el movimiento no hubiera alcanzado las dimensiones que alcanzó (Díaz del Moral, 1984: 282-283). Kaplan es mucho más clara en sus afirmaciones sobre la participación de los pequeños propietarios en los movimientos anarquistas. Según esta autora, Jerez de la Frontera “...tenía una militancia anarquista fuer- 
te en la que destacaban obreros cualificados y pequeños productores dependientes (pequeños viticultores)...,así como jornaleros agrícolas muy bien organizados..." (Kaplan, 1977: 238). y continúa: “...la ideología y la organización anarquista eran particularmente apropiados para los pequeños productores jerezanos...(debido a que) el anarquismo subrayaba las diferencias entre pobres y ricos...más que el conflicto entre obreros y patronos, como hacía el marxismo" (o. c., p. 239). Maurice se pliega en este terreno a los planteamientos de Kaplan e incluso los hace extensivos a otras zonas de Andalucía (Maurice, 1989: 388-389).

Pero los mismos autores y en los mismos trabajos aducen hechos y razones que vienen a desmentir esta supuesta alianza. Díaz del Moral afirma, en otro lugar, que "...los directores y casi la totalidad de los actores de la conmoción fueron obreros de la tierra" (Díaz del Moral, 1984: 282), y en el mismo sentido se pronuncia también en otras ocasiones (o. c.: 245,280 y 286 ). Kaplan asegura que “...la alianza populista que constituía la estrategia lógica para los pequeños productores no era necesariamente la doctrina más atractiva para los proletarios, que se veían regularmente enfrentados con sus patronos, grandes o pequeños, a propósito de salarios y de condiciones de trabajo" (Kaplan, 1977: 245). Maurice nos recuerda que también la opción mayoritaria por la que se decidieron las organizaciones anarquistas, la colectivización, alejó del movimiento a los pequeños propietarios (Maurice, 1989: 284-285).

Del relato que hace Rosado se deduce que la línea de separación en los conflictos que le tocó vivir estuvo entre los jornaleros u obreros sin tierra, por un lado, y el conjunto de los propietarios por otro (Rosado, 1979: 59-85). Y Brenan sitúa el problema del enfrentamiento de clase también con bastante claridad: "Desde 1850, y sin duda desde mucho antes, se ha dado una verdadera competición entre propietarios y braceros; los primeros, buscando el modo de pagar lo menos posible en jornales; los obreros trabajando lo menos posible a su vez...En esas ciudades, la atmósfera de odio entre las clases -del colono hacia el propietario; del proletariado sin tierra hacia todo el que lo contrata- hay que haberla vivido para poder creer en ella" (Brenan, 1962: 99-100).

Luque Baena, en su monografía de un pueblo granadino, al referirse a los años de la II República, menciona àlgunos hechos que vienen a confirmar en aquel caso esta separación rotunda entre obreros o jornaleros, por un lado, y patronos, por otro, que se produjo en la mayor parte de Andalucía. Allí dice que ser obrero, ser republicano y ser socialista se convirtió en una relación casi automática, como automática fue también la relación entre propietarios agrícolas (atención, no sólo grandes propietarios o medianos), sindicato patronal y posición política conservadora (Luque, 1974: 180-192). Malefakis tercia en la misma polémica y es concluyente: “...Su indigencia les condujo de vez en cuando a asociarse con los movimientos de protesta revolucionarios. Sin embargo, el campesinado pequeño propieta- 
rio representó en su conjunto...una fuerza de sostenimiento del orden social." (Malefakis, 1971: 123).

Y Díaz del Moral, refiriéndose a los años del "Trienio Bolchevique", tiene algunos pasajes aun más concluyentes, que ofrecen pocas dudas acerca de cual era la verdadera naturaleza de la polarización social en los pueblos cordobeses y las posiciones de clase respectivas. Intenta el notario de Bujalance dar razones de por qué la disputa política entre republicanos y liberales paso a segundo plano en los pueblos que estudió, y dice: “...existe una (razón), no peculiar de la provincia, sino común a toda Andalucía, y aun a buena parte de España. Aquí, como en todos los sitios donde la corriente del obrerismo fue muy intensa, ionizó el medio social: cationes y aniones, patronos y obreros, se amontonaron en los polos opuestos; no hubo lugar a términos medios...; cada cual se enroló en el bando adonde le empujaban sus intereses de clase... los propietarios y labradores, sin distinción de opiniones, acudieron a las organizaciones patronales..." (Díaz del Moral, 1984: 351).

No es nècesario que sigamos aportando más referencias para confirmar que, en lo fundamental, el conjunto de los propietarios agrícolas, pequeños y no pequeños, adoptaron una postura contraria a los movimientos sociales en el campo andaluz, que estuvieron protagonizados por los trabajadores sin tierra. Hay que desechar, por tanto, la idea de una comunidad de intereses entre jornaleros y pequeños propietarios en Andalucía, aunque ésta se haya producido coyunturalmente en algunos lugares. Ello no es ni con mucho la situación más frecuente. Pero, en los casos en que sí se produjo -significativamente allí donde los grandes terratenientes monopolizaban también la compra de la producción de los pequeños labradores, como ha sido frecuente en las comarcas vitivinícolas, en que los grandes propietarios agrícolas eran también grandes industriales bodegueros- seguiría siendo descabellado concebir la situación de la Andalucía rural de todo este siglo y en cualquier área, por más presencia del latifundio que pueda haber, como una situación caracterizada sólo en blanco y negro, por la presencia de una gran masa campesina sometida al poder de unas pocas familias granpropietarias, como se desprende del análisis de Sevilla-Guzmán y también, aunque de forma menos explícita, del de Martínez Alier, que menciona muy pocas veces a lo largo de su estudio la existencia de los pequeños y medianos propietarios. En Andalucía, desde hace mucho tiempo, puesto que las relaciones sociales de producción capitalistas se desarrollaron en el campo andaluz mucho antes de las desamortizaciones (Bernal, 1988), la adquisición de la tierra, su gestión, su transferencia, se rigen conforme a la lógica capitalista y este hecho primordial ha distanciado las posiciones de clase de los propietarios respecto a los no propietarios de tierra.

El conflicto social del campo andaluz desde el último tercio del siglo pasado y hasta la transición al régimen democrático, latente unas veces y manifiesto y virulento otras, fue 
un conflicto que enfrentó a dos conjuntos sociales producto del capitalismo: los no poseedoreś de tierra (obreros, la mayoría de ellos eventuales, aparceros, cierto tipo de colonos), y todos los propietarios de tierra más allá de esa estrecha franja de los que son primariamente jornaleros aunque tengan alguna pequeña propiedad. La razón fundamental que llevó al enfrentamiento a estas dos clases sociales no es, como se sostiene frecuentemente, que los idearios y programas anarquistas y socialistas atacaran al conjunto de la propiedad individual de la tierra, planteando diversas formas de colectivización. Tanto más cuanto que, con gran independencia de los idearios a los que formalmente daban su apoyo los adherentes a los movimientos anarquistas y socialistas, en la mayoría de ellos el deseo real era el reparto de la tierra en lotes familiares, como lo documentó perfectamente Díaz del Moral (1984: 199 y sig.). Pero tampoco cambiaron en lo sustancial las cosas a este respecto en la época que se instauró tras la muerte de Franco, pues, como demuestra Alfonso Ortí, entre los criterios de autoidentificación contrastiva empleados por los jornaleros por él estudiados en los años setenta, uno fundamental es el que los sitúa frente a propietarios o cultivadores directos: "...los asalariados de la agricultura se contraponen como una clase distinta, que privada de toda forma de posesión de la tierra, queda reducida a ser pura fuerza de trabajo, a constituir una clase de braceros sin más bien social que la oferta de sus brazos..." (Ortí, 1984: 213).

No se objetará, por último, que las organizaciones jornaleras que han tenido presencia en Andalucía desde los años de la Transición han sido justamente eso, organizaciones integradas exclusivamente por jornaleros $y$, en alguna menor medida, jornaleras, $y$ las acciones por ellos emprendidas, secundadas sólo por ellos y, si al caso, por algunos sectores minoritarios de los ámbitos urbanos. Se impone, por tanto, la consideración del movimiento jornalero andaluz como un movimiento de clase, propio de sociedades agrarias en las que se ha producido la división de clases típica de las sociedades capitalistas, con una imbricación o fusión sustancial de las estructuras rural y urbana previa. Esta es la conclusión inequívoca que se deriva del estudio de Alfonso Ortí, quien en otro texto ha analizado las profundas transformaciones que se han producido en el Estado español entre las pequeñas clases medias, especialmente, en los años sesenta y setenta. Según él, éstas se han caracterizado por el paulatino desplazamiento social y político de la vieja pequeña burguesía, nucleada en torno a la pequeña propiedad y a la pequeña producción (es decir, los estratos de campesinos tradicionales), por las nuevas clases medias -que él llama "clases funcionales"-, compuestas ante todo por técnicos y empleados (Ortí, 1987, pp. 724-725). Lo que no destaca suficientemente Ortí, a nuestro juicio, es que ese desplazamiento de la trascendencia social y política de las viejas clases medias ha sido posible sin especiales problemas porque en el cambio generacional las viejas clases medias han buscado, como una de sus estrategias principales, reconducir a sus hijos hacia las ocupaciones propias de las nuevas clases medias, de forma que, en una proporción importante, las "clases funcionales" de hoy son los 
hijos de la vieja pequeña burguesía patrimonial. En un contexto de este tipo, no se negará lo extemporáneo, lo obsoleto de cualquier análisis que contemple una sociedad rural o un mundo rural como algo distinto -y sometido además- al mundo urbano. En fin, la sociedad de los pueblos andaluces hace ya mucho tiempo que dejó de ser algo parecido a un mundo campesino, comunitario, del que globalmente pudiera surgir algún tipo de alianza o estrategia -empujada por los jornaleros- anticapitalista y procampesina.

\section{Los jornaleros reconsiderados}

Sin embargo, como decíamos al principio, tiene plena justificación considerar que los jornaleros andaluces de este largo siglo no son confundibles con la globalidad de los obreros. Vamos a intentar demostrarlo, pero utilizando un enfoque bien distinto al que hemos criticado anteriormente. El primer paso es constatar hechos, lo que, aunque parezca mentira, no se hace cuando los embrollos teóricos ocupan toda la atención. Los hechos son claros: hay un pasado de los jornaleros andaluces, cuyos últimos coletazos hemos conocido en los años de la transición política. que se caracteriza por el inconformismo y la recurrencia a la protesta. Sin embargo, hay un presente de los jornaleros andaluces que viene definido por la ausencia de protesta, el conformismo o, cuando menos, el desánimo y el escepticismo. Esto es lo que hay que explicar. Vamos a intentar hacerlo analizando la interrelación compleja que se da entre los contenidos culturales del sector social y los cambios en las relaciones sociales de producción a lo largo del períodn. Comprobaremos que es inadecuado intentar encontrar respuestas observando sólo las relaciones técnicas de trabajo, los procesos de trabajo concretos. aunque haya que considerarios. A este análisis ha de ensamblarse otro que tome en cuenta la trama general de las relaciones sociales e, incluso, el bagaje cultural, la memoria histórica del sector social, entendida como conjunto de instrumentos conceptuales de los que se sirven para interpretar el presente. Pero dejemos los prolegómenos y adentrémonos ya en la explicación de los hechos. Será la misma explicación la que aclare al lector las pautas metodológicas que hemos seguido.

La realidad de un sector social jornalero no confundible con la globalidad de la clase obrera tiene un reflejo evidente en el sello peculiar del movimiento jornalero andaluz respecto al movimiento obrero globalmente considerado. Es preciso reconocer la realidad de una identidad jornalera, con contenidos culturales en gran medida distintos a los de otros sectores de la clase obrera andaluza. Para comprobarlo, puede resultar oportuno fijar nuestra atención sobre alguno de esos contenidos culturales, que, aunque puedan parecerlo, no son circunstanciales o accesorios, pues constituyen algo así como ejes que han servido para articular respuestas globales y posicionamientos del sector social ante el resto de la sociedad. 
Una de esas ideas claves es la idea de "cumplir", un rasgo cultural no exclusivo de los jornaleros, pero que entre ellos ha tenido especial importancia. Este rasgo cultural fue ya subrayado por Martínez Alier (1968), quien le concedió la debida importancia, y ha sido resaltado después en algunos de los trabajos de I. Moreno $(1984,1993)$. Por nuestra parte, en diversos y dilatados trabajos de campo en las campiñas, en el Bajo Guadalquivir y en la Sierra Morena onubense, hemos podido comprobar la presencia todavía en los últimos años de este importante rasgo cultural (Talego, 1996a, 1996b, 1996c). En primera instancia, la idea de "cumplir", como ya sugirió Martínez Alier (1968:168, 190-91 y 334-35), indica la internalización por parte de los jornaleros de los intereses patronales; es decir, la asunción de una responsabilidad ante el trabajo jornalero que lo hace posible, con lo que parecen quedar a salvo los intereses de los propietarios. Pero el campo conceptual de la palabra, tal y como ha sido empleada por los jomaleros, es más denso: "cumplir" no ha sido sólo asumir la responsabilidad de hacer el trabajo "bien hecho" y en una medida razonable, para así ganar -o exigir- "en justicia" el salario. En nuestro trabajo de campo hemos comprobado una y otra vez -y así lo hemos reflejado- que esta idea implicaba también una consideración positiva, fundamental, del papel del jornalero en la producción agrícola, considerando su propio papel como esencial, por ser el que transforma la naturaleza y crea la riqueza. Esta forma de entender las relaciones sociales de producción les ha dado tradicionalmente fuerza moral para exigir mayores ventajas en el disfrute de la riqueza social, exigencia que han planteado de las más diversas formas en función de la coyuntura histórica y de las circunstancias políticas, desde la exigencia de subidas salariales y de mejoras en las condiciones de trabajo hasta el intento de transformación radical de las relaciones sociales de producción, para convertirse en dueños de la tierra, ya que, desde su percepción, son quienes con su trabajo le arrancan la riqueza. Aquel que no cumple o que no da su peoná no gana el derecho a convertirse en beneficiario y, en su caso, beneficiario principal (dueño en última instancia) de la riqueza de la tierra.

"Cumplir" se relaciona también con una convicción muy arraigada tradicionalmente en los jornaleros andaluces, como es que el único trabajo verdadero es el trabajo directo con el medio de producción fundamental, la tierra, considerando como superflua y opresiva la clase de los propietarios de la tierra y sus representantes, pero, más generalmente aun, las labores de gestión y burocráticas, juzgándolas prescindibles, superfluas o hasta onerosas -"vivir del cuento", dicen ${ }^{8}$ - para quienes de verdad viven del "trabajo-trabajo", del tra-

${ }^{8}$ En el trabajo de campo, en las entrevistas, las conversaciones con los jomaleros, les explicaba que mi trabajo (recalcando lo de trabajo) era hacer entrevistas, recopilar datos, etc. Ellos daban por buena mi explicación, ante todo porque comprendían que ese era mi medio de sustento, mi forma de "ganar el pan", pero no dejaban de considerar mi trabajo como de una naturaleza diferente al suyo, como menos trabajo o menos verdadero, no ya porque fuera más o menos "duro", sino por no considerarlo productivo. 
bajo verdadero. Para los jornaleros andaluces ha sido común considerar que la única o la fundamental riqueza es la riqueza agrícola.

A este importante rasgo cultural hay que añadir otro no menos relevante y que se desprende en parte del anterior: su convencimiento de que ellos mismos eran capaces de llevar con competencia la decisión y el control del trabajo en la tierra, como cualquier campesino productor, como lo hicieron, de hecho, cuando tuvieron oportunidad de acceder a aparcerías, a colonatos y otras formas de cesión del dominio directo sobre la producción. Es decir, su certeza del carácter injustificado y sobrante de los propietarios de la tierra que no la trabajan. Esta percepción de autosuficiencia se explica, parcialmente al menos, por las características del proceso de trabajo agrícola, por ser en él muy inferior el grado de organización y especialización administrativa y técnica requerido, en comparación con la industria.

Si éstas han sido algunas de las nociones centrales en torno al trabajo de los jornaleros andaluces, es fácil entender que desembocaran en la idea del derecho a la tierra por el trabajo. Esta es, de hecho, la convicción expresada en el grito más emblemático del movimiento jornalero andaluz a lo largo de toda su historia: la tierra para quien la trabaja. Esta creencia, conformadora fundamental de la identidad jornalera tradicional, delata una orientación cognitiva procampesina, más que genéricamente obrera; no supone tanto, o directamente, un cuestionamiento de la propiedad privada (concepción más propiamente obrera), como de la división y especialización social entre productores y gestores de la producción; no se ataca al dominio particular, familiar, sobre la tierra -sea como propiedad privada, sea bajo otras formas de posesión- sino al control del trabajo y del producto de unos por otros. Martínez Alier, en un estudio sobre campesinos peruanos (1973), llevado a cabo con posterioridad al realizado en Córdoba, captó más claramente esta concepción nuclear del pensamiento campesino, diferente a la mentalidad obrera, más centrada en el problema de la propiedad privada y con la expectativa de la colectivización socialista, como ha sabido contextualizar y teorizar I. Moreno, para quien, además, el arraigo del anarquismo en el movimiento jornalero andaluz se relaciona con esta orientación cognitiva (Moreno, 1993). Se trata, en definitiva, de un planteamiento radical y específicamente campesino que ha estado siempre latente y que se ha hecho manifiesto en todos los momentos históricos en que la lucha de clases les ha sido favorable: sobre todo en los años del "Trienio Bolchevique", los años de la II República y, en mucha menor medida, los años de la llamada "transición política a la democracia" (Díaz del Moral, 1984; Malefakis, 1971; Ortí, 1984, Talego, 1996a, 1996c).

Es en este sentido, muy distinto al que hemos cuestionado en el apartado anterior, como hay que entender a los jornaleros andaluces como campesinos sin tierra. Para nosotros es la orientación cognitiva, o más globalmente aun, la identidad global jornalera la que 
ha sido portadora de una serie de rasgos, al menos hasta las últimas décadas, que permiten definirla como básicamente_campesina. Esta interpretación no postula que los jornaleros hayan mantenido ninguna reminiscencia precapitalista en virtud de una pretendida "subsunción sólo formal" o de una supuesta igualdad o solidaridad con los campesinos pequeño propietarios. Los jornaleros son una clase social propia y característica del capitalismo agrario, plenamente vigente en Andalucía, por lo menos, desde la segunda mitad del pasado siglo. Lo campesino no constituye en el enfoque que sostenemos un mundo cultural distinto o previo al capitalista, sino la focalidad del problema del acceso a la tierra, pero en las condiciones propias de un capitalismo agrario.

Un enfoque así permite, además no tener que dar la espalda a las profundas modificaciones que han tenido lugar en la cultura del trabajo de los jornaleros andaluces en las últimas décadas, en las que no se negará que ese grito emblemático de la tierra para el que la trabaja ha perdido toda su fuerza, de forma que hoy es casi un recuerdo del pasado. Ciertamente, la rebeldía tradicional del sector social ha ido dejando paso a una situación de progresiva postración, a un cierto desánimo, pero también a un conformismo, pues, en general, perciben la situación actual como mejor o como "menos mala" de la que han conocido hasta los años sesenta o setenta. Tres son, a nuestro juicio, los factores fundamentales que han provocado estos cambios en su cultura del trabajo y en su identidad como sector social globalmente considerado: las profundas transformaciones acaecidas en el conjunto de la sociedad andaluza, la regularización de los subsidios estatales y, en parte, la menor jerarquización social interna de los núcleos rurales hoy en día.

Al mencionar los cambios generales en la sociedad andaluza nos referimos sobre todo al distinto papel que hoy desempeña el trabajo de los jornaleros en el conjunto de las relaciones económico-sociales del país: desde los años sesenta a la actualidad ha tenido lugar un proceso de emigración rural masiva, de los núcleos rurales a las ciudades y de Andalucía al exterior, emigración que ha sido protagonizada principalmente por ellos, aunque también por muchos pequeños propietarios; se ha producido también un crecimiento significativo de otros sectores productivos que han ganado en importancia relativa frente a la agricultura y que dejan sentir su influencia sobre las zonas rurales. Por lo demás, es un hecho que la tierra ha perdido importancia relativa como medio de producción y más aún como fuente demandante de trabajo, al tiempo que ha crecido enormemente la influencia de otros sectores productivos: se está muy lejos ya de aquella situación general en los pueblos andaluces en que la posesión o no de tierra era el marcador fundamental de las diferencias de clase e incluso de los niveles de vida y de los modelos de consumo; téngase en cuenta que, hasta los años sesenta, la diferencia entre tener y no tener tierra se traducía en una mínima estabilidad en el acceso a los bienes básicos y una cierta independencia o la amenaza constante de la miseria, de la necesidad de "robar pa comé" si el año era "malo 
de trabajo". Por si esto era poco, los jornaleros debían soportar una dependencia estrecha, casi axfisiante, de los patronos y sus representantes (capataces y manijeros), pues vivían pendientes, día tras día, de ser llamados a trabajar, o de no ser despedidos.

Sin embargo, en los últimos años, en los pueblos andaluces hay muchas personas que, sin tener vinculación directa con la tierra, gozan de posiciones sociales diversas, privilegiadas muchas veces, al tiempo que se han hecho más frecuentes los trabajadores que dependen de otros sectores productivos (construcción, servicios, sector público) y que gozan a menudo de condiciones más ventajosas que las del trabajo jornalero en el campo. Esta nueva situación ha hecho perder centralidad al trabajo de la tierra como medio percibido por los trabajadores del campo como fundamental para ganar el sustento $y$, en general, como fuente de la riqueza. Esta pérdida de centralidad de la tierra en la sociedad agraria andaluza es evidente en los últimos años, a pesar que sólo unos años antes, en la "transición política", la concentración de la tierra en grandes propiedades alcanzase todavía en Andalucía a ser un problema de primera magnitud política, hasta el punto que el problema (el latifundismo) y la vía para solucionarlo, es decir, la Reforma Agraria, fuera un marcador simbólico de identidad andaluz, que involucraba directamente y obligaba a posicionarse ante él, a la totalidad de los andaluces, como supo ver I. Moreno (1984). Probablemente se tratara del último resurgir del problema secular del "hambre de tierras" en Andalucía, de la "agonía final" (Ortí, 1984) del movimiento jornalero. Las condiciones sociales de Andalucía en la actualidad son diferentes a aquéllas en las que se forjaron las ideas centrales de la cultura del trabajo jornalera tradicional, tal y como las hemos caracterizado antes. Es lógico pensar que estos cambios sociales de carácter general han terminado afectando a contenidos importantes de la cultura del trabajo del sector social.

Pero, además, el modo de inserción del sector social en las relaciones sociales de producción agrícolas se ha modificado de forma importante: desde los años setenta en que entran en vigor las medidas de ayuda al desempleo. y especialmente desde 1984 que el Empleo Comunitario es sustituido por el Subsidio de Desempleo, los jornaleros han dejado de ser sólo trabajadores empleados eventualmente para ser también población subsidiada o sostenida parcialmente con los ingresos del Estado. Los subsidios serán todo lo precarios que se quiera, pero suponen una nueva fuente de ingresos para compensar la disminución de los ingresos salariales. Una fuente de ingresos que llega a las economías domésticas con regularidad (Palenzuela, 1993, Talego, 1996b). La existencia de estos subsidios se ha convertido en necesaria para la reproducción del sector social, que, por ello, ya no puede ser definido sólo como mano de obra eventual (un sector de la clase obrera), sino como un sector a caballo entre el salario productivo y el asistencial (pensiones subsidios). Un cambio de tal naturaleza en la ubicación del sector en las relaciones sociales de producción tiene, forzosamente, que provocar modificaciones profundas en sus pautas y sus concepcio- 
nes sobre el trabajo y sobre otros ámbitos de la realidad social, así como sobre el mismo Estado, como entidad que ya no es sólo policial y represiva, que deja de ser, en gran medida, la encarnación del enemigo de clase, convirtiéndose en instancia benefactora.

En lo que refiere más específicamente a las condiciones de vida, el Subsidio permite a las familias jornaleras un acceso relativamente holgado a los bienes de consumo básicos, lo que supone para ellos también una novedad, y tiene, por ello, gran relevancia para el sector social, pues no puede olvidarse que su memoria histórica -e incluso la experiencia vital de los más viejos- conserva demasiadas remembranzas y retazos de un pasado de penalidades, miseria e incluso hambre. Esto explica que en nuestro trabajo de campo de los últimos años con jornaleros, cuando nos hacían un balance de sus vidas, de las situaciones por las que pasaron, en una gran parte de los casos, el balance subjetivo del presente respecto al pasado era claramente favorable, siendo uno de los parámetros principales sobre los que construían su percepción, justamente, el nivel de satisfacción de las necesidades consideradas básicas, que en el presente, por primera vez, percibían cubiertas, sin holguras, parcamente, pero de forma estable. Un jornalero de Lebrija, conocido como Rubio Guajiro, nos resumió en una frase esta percepción general de la diferencia cualitativa entre el presente y el pasado: trabajo había mucho, pero con mucha hambre. Se trata de una frase construida desde la realidad actual en que el trabajo es muy escaso, pero que subraya también la distancia del hoy frente al pasado con la polaridad hambre/no hambre. Las "ayudas" del Estado, "el paro" como le llaman, es, piensan, el hecho principal que ha obrado el cambio. Esto no quiere decir que no perciban problemas serios, pues, tanto los más jóvenes como los más viejos, muestran gran preocupación por la falta de trabajo y la carencia de expectativas, pero ello no impide que perciban su situación actual como de relativa estabilidad -"estabilidad precaria" decíamos en otro lugar (Talego, 1996b)- y de mejora sustancial respecto al pasado.

Unase a ello, por último, un hecho también importante, que presenta variaciones de unas a otras comarcas, pero que se aprecia en todas partes: la menor dependencia objetiva de los jornaleros respecto a los propietarios de tierra de sus pueblos y comarcas. Es cierto que son los propietarios los facultados por el Estado para firmar el número de peonadas que los jornaleros necesitan para cobrar el subsidio (así se establece en la normativa que lo regula: Real Decreto 3237/83 de 28 de diciembre, BOE de 31 de diciembre), extremo este el más criticado por ellos al enjuiciar esa "ayuda". Pero esa dependencia de los jornaleros respecto a los propietarios no llega mucho más allá de la firma de las peonadas, pues en amplias zonas de la geografía andaluza este requisito burocrático es tan importante o más importante que la relación contractual laboral entre las dos partes, que es cada vez mas esporádica o casi inexistente. De cualquier forma, no puede soslayarse que los subsidios no son pagados por los propietarios locales, sino que les llegan directamente desde la admi- 
nistración, y que una porción importante de esos dineros la consiguen del trabajo en el PER que sufragan los ayuntamientos, y de otras obras públicas enfocadas, en mayor o menor medida, a solventar el desempleo local. Es más, en muchas comarcas serranas o incluso en las campiñas, la presencia de empresas públicas o semipúblicas -muchas compañías madereras y de gestión de espacios protegidos lo son o trabajan por lo menos para el Estado- ha crecido enormemente y han suplantado en buena medida a los propietarios como demandantes de mano de obra jornalera ${ }^{9}$.

Son éstos nuevos agentes sociales en el sector agrario andaluz, que ofertan mejores condiciones laborales y que se han convertido ya en muchas comarcas en la principal fuente de trabajo -casi única en los espacios adehesados y con presencia de monte-. Todos estos agentes tienen en común pertenecer o estar estrechamente ligados al sector público, como peritos, ingenieros, capataces, encargados, alcaldes (Talego, 1997). En un sentido amplio puede considerárseles a todos como intermediarios del Estado en el medio rural, llegando a constituir una nueva élite gerencial y a centralizar nuevas redes clientelares que redistribuyen recursos en forma de trabajo, contratos de obras, etc. Es un hecho que estas "nuevas clases medias" han desplazado en el medio rural el papel tradicional de propietarios y latifundistas, que han dejado de ser el centro de las redes clientelares para, incluso, pasar ellos a depender en mayor o menor grado de los agentes estatales, paraestatales o de las grandes firmas comerciales. En cuanto a los jornaleros, que son quienes nos interesan aquí, su papel dependiente no ha desaparecido, pero se ha desplazado significativamente: ya no son, $o$ lo son en mucha menor medida, los patronos locales el centro del poder social, quienes focalizan la dependencia, sino los agentes intermediarios a que nos referimos. Son tremendas las consecuencias sociales y políticas de esta nueva situación, aunque no se hayan puesto suficientemente de relieve: los jornaleros perciben, ante todo, que ha desaparecido o ha mermado su dependencia respecto a quienes tuvieron siempre el poder en los pueblos, ante quienes ellos vivenciaron la sumisión en los angostos límites de la sociedad local.

Frente a esta antigua sumisión, que tan evidentes y axfisiantes hacía los lazos de dependencia, la nueva red clientelar se presenta a ojos de los jornaleros más laxa, más liviana, por garantizarles mayor estabilidad (subsidios, mejores salarios, empleo frecuente de criterios imparciales para la contratación, etc.), pero también, y quizá más importante, por estar dirigida por personas nuevas, despojadas de los atributos y símbolos tradicionales del poder en los pueblos andaluces: los gerentes e intermediarios del presente son a menudo representantes políticos locales o están, por lo menos, cercanos a ellos, de forma que su imagen aparece próxima o confundida con la de quienes conforman las candidaturas loca-

${ }^{9}$ Como muestra, piénsese sólo en lo que significa en muchos pueblos la mano de obra destinada a prevención de incendios y a cuidado de espacios protegidos. 
les de los partidos gubernamentales. La imagen de todos ellos es, de alguna manera, la de los "representantes del pueblo" que, como tales, construyen su imagen como negociadores ante el exterior para traer recursos a la localidad. Se reconocerá que es más difícil para los jornaleros apreciar y sentir los nuevos vectores que tiene hoy la dependencia: no es lo mismo cuando la dependencia es entre vecinos que cuando todos los vecinos dependen por igual de un Estado que ya no es el Estado autoritario de hace unas décadas, sino un Estado benefactor que redistribuye recursos. Claro que son recursos escasos, pero son importantes para una cultura del trabajo jornalera fraguada en la precariedad y en la estrecha dependencia patronal.

El partido político que ha gobernado el Estado desde comienzos de los ochenta, el PSOE, ha conseguido capitalizar con gran éxito el favor político de los jornaleros andaluces y los pensionistas, por estas dos razones fundamentales: primero, por haber conseguido presentarse en los pueblos como la plataforma desde la que se realizaba ese papel de drenaje de recursos hacia los trabajadores, y segundo y más importante, por haber elaborado un discurso político que en su versión andaluza y localista enfatiza el enfrentamiento a los patronos tradicionales, a los "caciques". De esta forma, una estrategia de política económica diseñada a largo plazo desde postulados neoliberales, que ha perseguido la capitalización de las empresas agrarias y su readaptación a las nuevas condiciones de los mercados internacionales, ha recibido las bendiciones de los trabajadores del campo andaluz, aquellos que, precisamente eran el obstáculo principal (el estorbo) para el buen fin del proyecto: unos escuetos subsidios que poco significan en los presupuestos generales y buenas dosis de demagogia populista han sido los ingredientes de un hechizo cuyos efectos algunos quisiéramos ver desaparecer.

\section{BIBLIOGRAFÍA}

ABBAD, F., BERNAL, A.M. ET AL (1971): CLASSES DOMINANTES ET SOCIETE RURALE EN BASSE-ANdalousíe, Publications de la CaSa de VelázQuez, Madrid.

ACOSTA, J. (1979): Historia Y CULTURA DEL PUEblo ANDALUZ, BARCELONA, ANAGRAMA.

ALAVI, H. (1976): "LAS CLASES CAMPESINAS Y LAS LEALTADES PRIMORDIALES" (PP. 46-125), EN HOBSBAWM, E. Y ALAVI, H. (1976): LOS CAMPESINOS Y LA POLITICA, BARCELONA, ANAGRAMA.

ARTOLA, M.; BERNAL, A. M Y CONTRERAS; J. (1978): EL LATIFUNDIO. PRoPIEDAD Y EXPlotación. Siglos XVIII-XX, SERVICIO DE PUblicaciones AGRaRIas del MAPA.

BERNAL, A.M. (1974): LA PROPIEDAD DE LA TIERRA EN LAS LUCHAS AGRARIAS ANDALUZAS, ARIEL, BARCELONA.

- (1988): ECONOMÍA E HISTORIA DE LOS LATIFUNDIOS, MADRID, INSTITUTO DE EsPAÑA, ESPASACALPE. 
BRENAN, Y. (1962): EL LABERINTO ESPAÑOL. ANTECEDENTES SOCIALES Y POLÍTICOS DE LA GUERRA CIVIL, RuEdo IBÉRICO, PARÍS.

CALERO, A. M. (1976): Movimientos sociales en ANDALucia (1820-1936), MadRID, SIGLO XXI.

CHAYANOF, A. (1974): LA ORGANIZACIÓN DE LA UNIDAD ECONÓMICA CAMPESINA, BUENOS AIRES, NuEVA VISIÓN.

DÍAZ DEL MORAL, J. (1984): HISTORIA DE LAS AGITACIONES CAMPESINAS ANDALUZAS (ANTECEDENTES PARA UNA REFORMA AGRARIA), MADRID, AlIANZA EDITORIAL (1 ${ }^{\prime}$ ED. 1929).

FOSTER, G. (1964): LAS CULTURAS TRADICIONALES Y los CambIOS TÉCNICOS, MÉXICO, Fondo de Cultura Económico.

GALESKI, B. (1977): Sociología del Campesinado, Barcelona, PEnínsula.

GARRIDO, F. (1993): “EPÍlOGO: EL PROBLEMA DE LA TIERRA Y EL MOVIMIENTO JORNALERO ANDALUZ: ALGUNAS IDEAS DESDE LA ECOLOGÍA POLÍTICA", EN ECOLOGÍA, CAMPESINADO E hISTORIA, SEVILLA-GUZMÁN Y GONZÁLEZ DE MOLINA (EDS), MADRID, LA PIQUETA, PP. 429-437.

GARRIDO, L. (1979): Colectividades aGRARIAS EN ANDAlUCia: JAEN, I931-1939, Madrid, SIGLO XXI.

GODELIER, M., (1987): "INTRODUCCIÓN: EL ANÁLISIS DE LOS PROCESOS DE TRANSICIÓN", EN LOS PROCESOS DE TRANSICIÓN. ESTUDIOS DE CASOS ANTROPOLÓGICOS, REVISTA INTERNACIONAL DE CIENCIAS SOCIALES, UNESCO., PP. 3-15.

GONZÁLEZ DE MOLINA, M. (1993): "NuEVAS HIPÓTESIS SOBRE EL CAMPESINADO Y LA REVOluCión Liberal EN los CAMPOS de ANDALUCIA", EN SEVILLA-GUZMÁN y GONZÁlEZ DE MOLINA, Ecologia, campesinado e historia, MAdRID, La PiQueTA, PP. 267-308.

HOBSBAWM, E. Y ALAVI, H. (1976): Los CAMPESINOS Y LA POLITICA, BARCELONA, ANAGRAMA.

- (1983): REBELDES PRIMITIVOS. ESTUDIO SOBRE LAS FORMAS ARCAICAS DE LOS MOVIMIENTOS SOCIALES, BARCELONA, 1983.

HUIZER, G. (1973): EL POTENCIAL REVOLUCIONARIO DEL CAMPESINADO EN AMÉRICA LATINA, México, Siglo XXI.

KAPLAN, T. (1977): ORÍGENES SOCIALES DEL ANARQUISMO EN ANDALUCÍA. CAPITALISMO AGRARIO Y LUCHA DE CLASES EN LA PROVINCIA DE CÁDIZ, 1868-1903, BARCELONA, CRÍTICA.

KAUTSKY, K. (1974): LA CUESTIÓN AGRARIA, BARCELONA, LAIA.

LEHMANN, D. Y ZEMELMAN, H. (1975): EL CAMPESINADO: CLASE Y CONCIENCIA DE CLASE, BuENOS AIRES, NuEVA Visión.

LUQUE, E. (1974): ESTUDIO ANTROPOLÓGICO DE UN PUEBLO DEL SUR, MADRID, TECNOS.

MARTÍNEZ ALIER, J. (1968): LA ESTABILIDAD DEL LATIFUNDISMO. ANÁLISIS DE LA INTERDEPENDENCIA ENTRE RELACIONES DE PRODUCCIÓN Y CONCIENCIA SOCIAL EN LA AGRICULTURA latifundista de la Campiña de Córdoba, París, Ruedo IbÉrico. 
- (1973): Los hUACHILLEROS DEL PERÚ. DOS ESTUdIOS DE FORMACIONES SOCIALES AGRARIAS, PARÍs, RUEDO IBÉRICO.

MARTÍNEZ, M. R. (1993): LAS EXPRESIONES CULTURALES DEL PROBLEMA DE LA TIERRA EN ANDALUCÍA EN EL PRIMER TERCIO DEL SIGLO XX, SEVILLA, FUNDACIÓN BLAS INFANTE.

MALEFAKIS, E. (1971): REFORMA AGRARIA Y REVOLUCIÓN CAMPESINA EN LA ESPAÑA DEL SI$G L O X X$, ARIEL, BARCELONA.

MAURICE, J. (1989): EL ANARQUISMO ANDALUZ. CAMPESINOS Y SINDICALISTAS, 1868-1936, BARCELONA, EDITORIAL CRÍTICA.

MORENO, I. (1984): "REFORMA AGRARIA E IDENTIDAD ANDALUZA. IMPLICACIONES SIMBÓlICAS DEL PROBLEMA DE LA TIERRA EN ANDALUCÍA", PONENCIA PRESENTADA A LAS "JORNADAS SOBRE LA TIERRA", JEREZ, FEBRERO DE 1984, PUBLICADA EN NACIÓN ANDALUZA, № 2-3, GRANADA, PP. 91-96. TAMBIÉN EN ANDALUCIA: IDENTIDAD Y CULTURA (ESTUDIOS DE ANTRopología ANDALUZA), PP. 43-52, Málaga, EdITORIAL Librería ÁGORA, 1993.

- (1991): "IDENTIDADES Y RITUALES. ESTUDIO INTRODUCTORIO", EN PRAT, J., MARTÍNEZ, U., CONTRERAS, J. Y MORENO, I., (COMP), ANTROPOLOGÍA DE LOS PUEBLOS DE ESPA$\bar{N} A$, MADRID, ED. TAURUS, PPS 601-636.

- (1993): “CultuRA DEL TRABAJO E IDEOLOGÍA: El MOVIMIENTO CAMPESINO ANARQUISTA ANDALUZ", ANDALUCIA: IDENTIDAD Y CULTURA (ESTUDIOS DE ANTROPOLOGÍA ANDALUZA), PP. 53-68, MÁlAGA, EdITORIAL Librería ÁGORA.

ORTÍ, A. (1984): "CRISIS DEL MODELO NEOCAPITALISTA Y REPRODUCCIÓN DEL PROLETARIADO RURAL (REPRESIÓN, RESURRECCIÓN Y AGONIA FINAL DE LA CONCIENCIA JORNALERA)", SOBRE AGRICULTORES Y CAMPESINOS, AA.VV, SERVICIO DE PUBliCACIONES AGRARIAS DEL MAPA, PP.167-251.

- (1987): "ESTRATIFICACIÓN SOCIAL Y ESTRUCTURA DE PODER: VIEJAS Y NUEVAS CLASES MEdias en la ReCONSTRUCCIÓN de la hegemonía buRguesa", Política Y SOCIEDad. EsTUdIOS EN HOMENAJE A FRANCISCO MURILLO FERROL, VOL. II, ED. CENTRO DE INVESTIGACIONES SOCIOLOGICAS y CENTRO de ESTUdios CONSTITUCIONALES, PP. 711-736.

PALENZUELA, P. (1993): “ANTROPOLOGÍA ECONÓMICA DEL CAMPESINADO ANDALUZ”, EN SEVILLA-GUZMÁN, E. Y GONZÁLEZ DE MOLINA, M. (COORDS), ECología, CAMPESINADO E HISTORIA, MADRID, ED. LA PIQUETA, PP. 357-374.

REDFIELD, R. (1955): THE LITTLE COMMUNITY, THE UNIVERSITY OF ChICAGo PREsS, 1955.

ROSADO, A. (1979): TIERRA Y LIBERTAD. MEMORIAS DE UN CAMPESINO ANRCOSINDICALISTA ANDALUZ, BARCELONA, CRÍTICA.

SEVILLA GUZMÁN Y PÉREZ YRUELA (1976): "PARA UNA DEFINICIÓN SOCIOLÓGICA DEL CAMPESINADO", AGRICULTURA Y SOCIEDAD, № 1, PP. 7-38, MADRID, MAPA.

SEVILLA-GUZMÁN, E. (1979): LA EVOLUCIÓN DEL CAMPESINADO EN ESPAÑA. ELEMENTOS para una sociología política del Campesinado, PEnínsula, Barcelona. 
- (1980): "REFLEXIONES TEÓRICAS SOBRE El CONCEPTO SOCIOLÓGICO DE LATIFUNDISMO", EN BARROS, A. (ED.) A Agricultura Latifundiaria na PENínsula IbÉRICA, Lisboa, FunDAÇAo Calouste GulbenhKian, PP. 29-46.

- (1988): “ANARQUISMO AGRARIO", EN ANARQUISMO Y MOVIMIENTO JORNALERO EN ANDALUCÍA, CÓRDOBA, AYUNTAMIENTO DE CÓRDOBA, PP. 23-46.

SEVILLA-GUZMÁN Y GONZÁLEZ DE MOLINA, M. (1993): "ECOLOGÍA, CAMPESINAdo E HISTORIA: PARA UNA REINTERPRETACIÓN DEL DESARROLLO DEL CAPITALISMO EN LA AGRICULTURA", EN SEVILLA-GUZMÁN Y GONZÁLEZ DE MOLINA, M, ECOLOgía, CAMPESINADO E HISTORIA, MADRID, LA PIQUETA, PP. 23-130.

SHANIN, T. (1979A): "El CAMPESINADO COMO FACTOR POLÍTICO", EN SHANIN, T (ED.): Campesinos y Sociedades Campesinas, México, Fondo de Cultura Económico.

- (1983): LA CLASE INCÓMODA. SOCIOLOGÍA POLÍTICA DEL CAMPESINADO EN UNA SOCIEDAD EN DESARROLLO (RUSIA 1910-1925), MADRID, AliANZA EdITORIAL.

TALEGO, F. (1993): "LOS GRUPOS DOMÉSTICOS JORNALEROS: PRODUCCIÓN DE HIJOS Y PREPA-

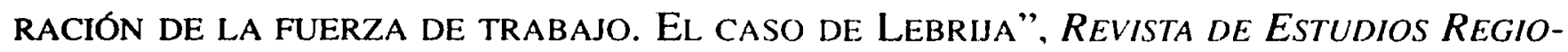
NALES, № 41 , PP. 205-230.

- (1995): "CUlTURA DEL TRABAJO JORNALERA, DISCURSO POLÍTICO Y LIDERAZGO: EL CASO DEL PODER POPUlar de Marinaleda" Revista de ANTRopología Social, № 4, MadRid,

$\therefore$ Servicio de Publicaciones de la Universidad Complutense PP. 131-151,

- (1996A): CULTURA JORNALERA, “PODER POPULAR" Y LIDERAZGO MESIÁNICO. ANTROPOLOGÍA política de Marinaleda, Sevilla, Universidad de Sevilla y Fundación Blas INFANTE.

- (1996B): ENTRE EL TRABAJO Y LOS SUBSIDIOS DEL ESTADO: LOS JORNALEROS DE LEBRIJA, SEVILla, HeRmandad de los SANTOS DE LebriJa.

- (1996C): "El <<HAMBRE DE TIERRAS> EN AROCHE Y SU REFLEJO EN LA EXPLOTACIÓN DE LA CONTIENDA (1920-1980), I JORNADAS TRANSFRONTERIZAS SOBRE LAS CONTIENDAS HISPANOportuguesas. ao ENCONTRO da CONTENDA, Universidad de HuElva y Nova DE LisBOA, PP 159-187.

- (1997): "El PODER DE LOS ALCALDES EN LOS PUEBLOS: UNA APROXIMACIÓN DESDE LA ANtropología Social", Demófilo, REVISTa de Cultura Tradicional de ANDalucía, SeVILLA, E/P.

TUÑÓN DE LARA, M. (1978): LUCHAS OBRERAS Y CAMPESINAS EN LA ANDALUCÍA DEL SIGLO $X X$. JAEN (1917-1920), SEVILla (1930-1932), MADRID, Siglo XXI.

WOLF, E. (1971): LOS CAMPESINOS, BARCELONA, LABOR.

- (1972): LAS luChas CAMPESINAS del Siglo XX, MÉXICO, Siglo XXI. 